\title{
Entacapone is beneficial in both fluctuating and non-fluctuating patients with Parkinson's disease: a randomised, placebo controlled, double blind, six month study
}

\author{
D J Brooks, H Sagar, and the UK-Irish Entacapone Study Group
}

J Neurol Neurosurg Psychiatry 2003;74:1071-1079

See end of article for authors' affiliations

....................

Correspondence to:

Professor David J Brooks, MRC Cyclotron Building,

Hammersmith Hospital, Du

Cane Road, London

W12 ONN, UK;

david.brooks@csc.mrc.ac.uk

Received 27 March 2002

In revised form

9 September 2002

Accepted

28 January 2003

Objective: To study the effect of entacapone, a specific peripherally acting catechol-Omethyltransferase (COMT) inhibitor used in combination with levodopa treatment, in cases of Parkinson's disease with both fluctuating and non-fluctuating response to treatment.

Methods: A randomised, placebo controlled, double blind, six month study was undertaken in 172 fluctuating and 128 non-fluctuating patients. The clinical efficacy and safety of $200 \mathrm{mg}$ entacapone given with each daily levodopa dose was studied. Efficacy was examined using home diaries, the unified Parkinson disease rating scale (UPDRS), and recording of daily levodopa dose.

Results: The primary efficacy variable for fluctuating patients-the proportion of daily $\mathrm{ON}$ time-showed a significant increase compared with placebo $(p<0.05)$. The absolute $O N$ time (mean (SD)) increased from $9.5(2.5)$ to $10.8(2.4)$ hours $(p<0.01)$, and the daily OFF time was correspondingly reduced from $7.0(2.6)$ to 5.9 (2.5) hours ( $p<0.05 v$ placebo). This improvement was achieved despite a reduction in daily levodopa requirements. The effect was rapidly lost on withdrawal of entacapone. In non-fluctuating patients, the primary efficacy measure was part II of the UPDRS (activities of daily living; $A D L)$. In this group of patients, $A D L$ scores improved in the entacapone group $(p<0.01 v$ placebo), and there was also a $40 \mathrm{mg}$ reduction in levodopa requirement ( $p<0.01 v$ placebo). Entacapone was well tolerated by both fluctuating and non-fluctuating patients.

Conclusions: The ability of entacapone to provide additional benefits to levodopa treatment in increasing $\mathrm{ON}$ time in fluctuating Parkinson's disease patients was confirmed. A novel finding was that patients without fluctuations also obtained benefit from the addition of entacapone to their levodopa treatment, as evidenced by improved ADL scores and a relatively reduced levodopa requirement.

$\mathrm{T}$ he combination of levodopa and a peripherally acting dopa decarboxylase (DDC) inhibitor continues to be the mainstay and most effective symptomatic treatment of Parkinson's disease. ${ }^{12}$ It provides relief from the symptoms and signs of this condition in both the early and the late stages of the disease. During the years of disease progression, however, the therapeutic plasma levodopa window becomes narrowed, leading to various motor complications, ${ }^{3}$ the most common of which are end-of-dose motor fluctuations (wearing off) and peak dose dyskinesias. The prevalence of wearing off varies markedly according to different reports, ranging from $20 \%$ to $60 \%$ within five years, ${ }^{4-7}$ The older and higher figures seem, however, to be an overestimate.

In order to reduce these motor complications, several levodopa regime modification strategies have been used. ${ }^{189}$ Increasing the size of individual levodopa doses usually leads to increased severity of dyskinesias, without marked prolongation of the benefit of levodopa. Studies with controlled release (CR) levodopa preparations have shown conflicting results, some reporting a significant clinical benefit, others reporting no difference at all in comparison with standard levodopa preparations. ${ }^{10-13}$ Current practice is therefore to increase the dosing frequency and to use the smallest possible individual doses of levodopa. ${ }^{189}$ While this can reduce fluctuations for some patients, it may lead to intermittent re-emergence of symptoms because of suboptimal levodopa exposure.

Thus one of the most important goals in levodopa treatment is to prolong the duration of its antiparkinsonian effects without increasing peak plasma concentrations, in order to provide a longer duration of benefit without disabling dyskinesias. This may be achieved by giving levodopa and a DDC inhibitor in combination with a peripheral inhibitor of the enzyme catechol-O-methyltransferase (COMT). ${ }^{1891415}$ When Coadministered with a DDC inhibitor, levodopa is mainly metabolised by COMT in the periphery. Two COMT inhibitors have recently been developed, the peripherally-only acting entacapone, and tolcapone, which probably also has some central activity. ${ }^{14-17}$ When entacapone or tolcapone is given in combination with standard levodopa preparations, single doses prolong the plasma half life of levodopa, thus increasing its bioavailability without altering the peak concentration $\left(\mathrm{C}_{\max }\right) \cdot{ }^{18}$ In levodopa treated patients with motor fluctuations, a COMT inhibitor prolongs the therapeutic response compared with levodopa alone. ${ }^{19-23}$

Administration of a COMT inhibitor concomitantly with levodopa reduces the peak-trough levodopa variations compared with levodopa alone. ${ }^{20} 24$ This leads to more stable plasma levodopa concentrations through the day and to fewer daily fluctuations in the patient's clinical condition. In summary, COMT inhibitors have been reported to produce a more stable pharmacokinetic profile of levodopa and so improve the management of patients with motor fluctuations.

The treatment of patients without motor fluctuations is less complicated. However, in a recent population based study, Larsen et al showed that non-fluctuators still experienced significant disability (bradykinesia, fatigue, sleep disturbances, depression) despite drug treatment, ${ }^{7}$ and that their quality of life was markedly poorer than in an age and sex matched general population..$^{25}$ Indeed, while patients without fluctuations 
Table 1 Demographics at baseline and history of Parkinson's disease

\begin{tabular}{|c|c|c|c|c|}
\hline \multirow[b]{2}{*}{ Variable } & \multicolumn{2}{|c|}{$\begin{array}{l}\text { Fluctuating patients } \\
(n=172)\end{array}$} & \multicolumn{2}{|c|}{$\begin{array}{l}\text { Non-fluctuating patients } \\
(n=128)\end{array}$} \\
\hline & $\begin{array}{l}\text { Entacapone } \\
(n=115)\end{array}$ & $\begin{array}{l}\text { Placebo } \\
(n=57)\end{array}$ & $\begin{array}{l}\text { Entacapone } \\
(n=88)\end{array}$ & $\begin{array}{l}\text { Placebo } \\
(n=40)\end{array}$ \\
\hline \multicolumn{5}{|l|}{$\operatorname{Sex}(n(\%))$} \\
\hline Male & $69(60.0 \%)$ & $40(70.2 \%)$ & $63(71.6 \%)$ & $28(70.0 \%)$ \\
\hline Female & $46(40.0 \%)$ & $17(29.8 \%)$ & $25(28.4 \%)$ & $12(30.0 \%)$ \\
\hline Age (years) & $65.9(8.9)$ & $64.7(8.5)$ & $67.8(9.4)$ & $68.1(8.9)$ \\
\hline Weight (kg) & $68.4(14.3)$ & $70.3(13.6)$ & $73.9(14.7)$ & 75.7 (12.1) \\
\hline Age at onset of PD (years) & $56.9(10.3)$ & $56.2(9.0)$ & 62.9 (11.0) & $63.1(9.0)$ \\
\hline Duration of PD (years) & $9.6(5.1)$ & $9.1(5.3)$ & $5.4(4.8)$ & $5.6(4.6)$ \\
\hline Occurrence of dyskinesias* (n (\%)) & $60(54.4 \%)$ & $38(71.7 \%)$ & $11(12.6 \%)$ & $8(21.1 \%)$ \\
\hline Duration of levodopa treatment (years) & $8.1(4.6)$ & $7.7(4.9)$ & $3.7(3.9)$ & $3.8(3.8)$ \\
\hline Daily levodopa dose (mg) & $682(390)$ & $712(369)$ & $500(259)$ & $524(335)$ \\
\hline Standard levodopa only (n (\%)) & $46(40.7 \%)$ & $29(53.7 \%)$ & $43(51.8 \%)$ & $29(72.5 \%)$ \\
\hline CR levodopa only (n (\%)) & $31(27.4 \%)$ & $12(22.2 \%)$ & $17(20.5 \%)$ & $4(10.0 \%)$ \\
\hline Standard and CR levodopa (n (\%)) & $36(31.9 \%)$ & $13(24.1 \%)$ & $23(27.7 \%)$ & 7 (17.5\%) \\
\hline Other antiparkinsonian drugs (n $(\%)$ ) & $77(67.0 \%)$ & $41(71.9 \%)$ & $28(31.8 \%)$ & $14(35.0 \%)$ \\
\hline Dopamine agonists & $46(40.0 \%)$ & $20(35.1 \%)$ & $8(9.1 \%)$ & $8(20.0 \%)$ \\
\hline Selegiline & $38(33.0 \%)$ & $26(45.6 \%)$ & $16(18.2 \%)$ & $4(10.0 \%)$ \\
\hline Anticholinergics & $16(14.0 \%)$ & $10(17.6 \%)$ & $5(5.7 \%)$ & $6(15.0 \%)$ \\
\hline Amantadine & $4(3.5)$ & - & $4(4.5 \%)$ & $1(2.5 \%)$ \\
\hline \multicolumn{5}{|c|}{$\begin{array}{l}\text { Values are mean (SD) or } \mathrm{n}(\%) \\
\text { *UPDRS, question } 32 \text {. } \\
\text { CR, controlled release; PD, Parkinson's disease. }\end{array}$} \\
\hline
\end{tabular}

treated with small doses of dopaminergic drugs gain relief, they can still remain bradykinetic. ${ }^{25}$ In studies testing the efficacy of tolcapone in non-fluctuating patients with Parkinson's disease, quality of life (measured as activities of daily living, ADL) and motor scores on the unified Parkinson's disease rating scale (UPDRS) both improved, suggesting that COMT inhibitors may also benefit these patients. ${ }^{26} 27$

So far, four randomised, placebo controlled, double blind, long term (6-12) month studies with entacapone have been reported. ${ }^{28-31}$ Although one of these studies included a small sample of non-fluctuating patients, ${ }^{31}$ most of the patients studied showed typical wearing off type motor fluctuations. Entacapone given in combination with levodopa has been shown to be clinically and statistically superior to placebo in prolonging $\mathrm{ON}$ time in those studies.

The present randomised, placebo controlled, double blind, six month study was designed to evaluate the effect of entacapone in both fluctuating and non-fluctuating patients in parallel. In fluctuating patients, the efficacy of entacapone was evaluated by home diary data detailing ON and OFF times. In the non-fluctuating patients, efficacy was judged by the ADL scores of the UPDRS. The effect of withdrawal of entacapone (and placebo) was also measured.

\section{METHODS \\ Patients}

Three hundred patients with idiopathic Parkinson's disease were included in the study. The patients were recruited from 29 neurology and movement disorder clinics in the United Kingdom and the Republic of Ireland. Patients without fluctuations as well as those with more advanced disease associated with fluctuating motor responses to levodopa, as classified by home diaries, were included. All patients were being treated with levodopa, either as a standard formulation alone, as a CR levodopa preparation alone, or as a combination of these. Other antiparkinsonian drugs, such as dopamine agonists and selegiline, were also allowed, whereas apomorphine was not (table 1). The patients' antiparkinsonian drug treatment had to remain stable for at least four weeks before randomisation. Before study entry, the treatment was stabilised individually for each patient to optimal clinical response according to the normal clinical practice of the patients' physicians. However, despite this optimisation the physicians considered that the patients could benefit from combining entacapone with their current levodopa treatment because of different parkinsonian symptoms.

Patients excluded from the trial included those with symptoms suggestive of atypical parkinsonism, dementia, other significant neurological diseases, psychiatric disorders, or severe systemic illnesses. Fertile women and patients with clinically relevant laboratory values outside the normal range or ECG findings not related to a chronic stable disease were also excluded. Patients were not allowed to use non-selective monoamine oxidase inhibitors or drugs having an antidopaminergic action.

The study was conducted according to the principles of the Declaration of Helsinki, and was approved by the ethics committees of all participating centres. All patients gave their signed informed consent after receiving verbal and written information about the study.

\section{Study design}

The study followed a randomised, double blind, placebo controlled, parallel group design over six months. The patients were also stratified into two groups-fluctuators and nonfluctuators. The study started with a two to four week screening period, which was followed by a six month, double blind period of study treatment, and a two week washout period without study treatment. Study visits were at baseline (visit 1 ), and at $0.5,1.5,4$, and 6 months (visits 2 to 5 ) after the baseline visit. The post-study visit (visit 6) was two weeks after the visit 5 .

The investigational treatment was $200 \mathrm{mg}$ entacapone (Comtess, Orion Pharma, Espoo, Finland) or an identical placebo tablet, taken concomitantly with each scheduled daily levodopa dose, the intake varying from two to 10 tablets a day. At visit 1, the patients were randomised in a 2:1 ratio to entacapone or placebo. Occasional booster doses of levodopa were allowed to relieve unpredictable OFF periods in fluctuating subjects, but the study drug was not taken with these booster doses.

Criteria for withdrawal from the study included an adverse event or a serious adverse event requiring discontinuation of study treatment; use of any prohibited concomitant drugs; withdrawal of consent at any time; or at the investigator's discretion. 


\section{Treatment assignment}

The patients were randomised separately for each centre. Patients were first stratified into two groups according to fluctuating and non-fluctuating symptoms, and then separately randomised within these groups to the two parallel treatment groups. The randomisation was carried out by the department of biostatistics of Orion Pharma, using a computerised method.

Before the start of the study, the patients who described having a fluctuating response to levodopa were given 24 hour home diaries. These patients with symptoms indicative of motor fluctuations (end-of-dose deterioration)-including early morning akinesia, nocturnal akinesia, or wearing off-were asked to record ON, OFF, or ASLEEP time in 30 minute intervals for the three days before each visit.

ON state was defined as the time when the patients were free of many parkinsonian symptoms. OFF state was defined as the time when the patients had parkinsonian symptoms from which they were free when they had benefit from their antiparkinsonian drugs.

Those patients who had $\geqslant 0.5$ hours OFF time on each day, and whose cumulative OFF time was $\geqslant 4.5$ hours over the three diary days at baseline were classified as fluctuators. All other patients were classified as non-fluctuators.

\section{Primary and secondary outcome measures Fluctuating patients}

The primary efficacy variable for the fluctuating patients was the proportion of daily ON time (\%) while awake, collected from home diaries and counted over three consecutive days before each study visit. Secondary efficacy variables were absolute ON and OFF times as well as daily levodopa dosages recorded on home diaries. Data from the UPDRS subscores of parts I, II, III, the total score (parts I to III), and the scheduled daily levodopa dose were also recorded. ${ }^{32}$ Part III was evaluated in the ON state on an average two hours after the intake of levodopa. A clinical seven point global score $(+3$, very well to -3 , very poorly) characterising the patient's condition during the week preceding the study visit was completed by the investigators, based on information received from the patient.

\section{Non-fluctuating patients}

The primary efficacy variable for non-fluctuating patients was the ADL subscale score (part II) of the UPDRS. In addition, parts I and III, the sum of parts I to III, and the scheduled daily levodopa dose were used as secondary efficacy variables. The motor score (part III) was evaluated on an average two and a half hours after the intake of levodopa. The global score as described above was completed by the investigators.

The safety of entacapone was assessed by safety laboratory tests, ECG recording, vital signs, and adverse event recording. Adverse events were defined according to the WHO classification. The assessment of patient compliance was based on a study drug tablet count. All variables were evaluated at each visit.

\section{Sample size}

Originally, it was planned that 400 patients would be recruited: half with and half without motor fluctuations. It was estimated that 200 fluctuating patients would provide a sufficient sample size for evaluating changes in the proportion of daily ON time. This estimate was made on the following assumption: to detect a difference of one hour in mean ON time between the treatment groups (entacapone $v$ placebo; with a standard deviation of 1.3 hours, a two sided significance level of $5 \%$, and a power of $95 \%$ ) at least 50 patients would be needed in each treatment group. The calculations were based on a two-sample $t$ test, without adjusting for multiple time points. The $2: 1$ randomisation between the treatment groups (entacapone $v$ placebo) was not considered to decrease power, because the standard deviation in the treatment groups was roughly the same.

In addition, it was planned that 200 non-fluctuators would be recruited. No formal sample size calculation was done for these patients, as at the time of planning this trial we had no experience of the use of the ADL score in non-fluctuating patients.

Eventually, 300 patients were randomised after the original recruitment period had been extended by several months. However, the sample size of 172 for fluctuating patients and 128 for non-fluctuating patients was considered adequate to reach statistical conclusions.

\section{Statistical methods}

The evaluations of the primary efficacy variables in both fluctuating and non-fluctuating patients were done according to the intention to treat (ITT) principle using observed cases (ITT-OC). Patients with at least one efficacy measurement on study treatment were included in the efficacy analysis.

The efficacy variables (home diary data, UPDRS scores, and levodopa dose) were evaluated by analysis of covariance (ANCOVA) for repeated measures, using the response at months 4 and 6 to estimate the treatment difference between the groups. This approach was intended to minimise the possible bias caused by the variability of data over time, as the influence of individual time points became smaller. The withdrawal effects for all these variables were assessed by comparing results from the post-study visit (visit 6) with those from the final study visit (visit 5). The ANCOVA model controlled for treatment, time, their interaction, centre, and centre by treatment interaction. The baseline measurement was used as a covariate. Patients with 0 hours of daily ON time were excluded from the analysis of home diary variables.

Efficacy variables were analysed separately for fluctuating and non-fluctuating patients. A two way significance level of $5 \%$ was considered statistically significant. All randomised patients who had taken at least one dose of study drug were included in the safety analysis.

\section{RESULTS}

\section{Patient data}

Of the 348 Parkinson's disease patients originally recruited for the study, 48 were excluded after screening: 20 did not fulfil the inclusion criteria, 11 withdrew their consent, one had an adverse event, one was unable to complete the home diary, and no specific reason was given for 15 patients. Thus 300 patients were randomised. About $20 \%$ of all patients dropped out during the study, mostly because of adverse events (table 2, fig 1).

Overall, 172 patients had fluctuations (57\%) and 128 were non-fluctuators $(43 \%)$. The non-fluctuators were on average two to three years older, and their age at onset of Parkinson's disease was six to seven years greater, than the fluctuators. The mean duration of levodopa treatment was four to five years longer, and the daily levodopa dose approximately $200 \mathrm{mg}$ higher in the fluctuating compared with the non-fluctuating patients. Most patients used standard levodopa rather than CR preparations. Most of the fluctuating patients were taking other antiparkinsonian drugs in addition to levodopa-in particular dopamine agonists and selegiline-but this was less common in the non-fluctuating patients. The baseline demographic characteristics of patients in the two entacapone groups were comparable with their respective placebo control groups and are presented in table 1 . The average compliance as determined by tablet count was good, varying from $98 \%$ to $101 \%$.

\section{Efficacy}

Fluctuating patients

Entacapone significantly increased the proportion of daily ON time, the primary efficacy variable, from $58 \%$ to $65 \%$ (p $<0.05$ 
Table 2 Discontinuations in fluctuating and non-fluctuating patients

\begin{tabular}{llllll}
\hline \multirow{2}{*}{$\begin{array}{l}\text { Reason for } \\
\text { discontinuation }\end{array}$} & \multicolumn{2}{c}{ Entacapone $(\mathrm{n}=203)$} & & \multicolumn{2}{c}{ Placebo $(\mathrm{n}=97)$} \\
\cline { 2 - 3 } \cline { 5 - 6 } & $\mathrm{n}$ & $\%$ & & $\mathrm{n}$ & $\%$ \\
\hline Completed & 154 & 75.9 & & 81 & 83.5 \\
Discontinued (total) & 49 & 24.1 & & 16 & 16.5 \\
$\quad$ Deaths & $1^{*}$ & 0.5 & & 0 & 0 \\
AE & 38 & 18.7 & & 14 & 14.4 \\
Dopaminergic AE & 12 & 5.9 & & 1 & 10 \\
$\quad$ Dyskinesias & 6 & 3.0 & & 0 & 0 \\
$\quad$ Hallucinations & 3 & 1.5 & & 1 & 1.0 \\
$\quad$ Nausea & 3 & 1.5 & & 0 & 0 \\
Non-dopaminergic AE & 26 & 12.8 & & 13 & 13.4 \\
Intercurrent illness & 1 & 0.5 & & 0 & 0 \\
Non-compliance & 2 & 1.0 & & 0 & 0 \\
Protocol violation & 3 & 1.5 & & 2 & 2.1 \\
Lost to follow up & 1 & 0.5 & & 0 & 0 \\
Other & 4 & 2.0 & & 0 & 0 \\
\hline
\end{tabular}

*Coronary artery bypass operation and later a massive myocardial infarction and stroke about one month after completing the study. $\mathrm{AE}$, adverse events.

$v$ placebo) (table 3, fig 2). The absolute ON time increased significantly ( $p<0.01$ ), with a difference of 1.2 hours between the entacapone and placebo groups. The absolute OFF time decreased correspondingly (table 3; $p<0.05 v$ placebo). Based on home diaries, the mean daily levodopa dose was decreased in the entacapone group by $33 \mathrm{mg}$ and increased in the placebo group by $26 \mathrm{mg}$ ( $\mathrm{p}<0.001$ ) (fig 3 ).

There were no statistically significant differences between the entacapone and placebo groups for parts II (ADL) and III (motor) subscales of the UPDRS. Although part I scores (mentation, behaviour, and mood) deteriorated in the entacapone group, the mean change was minor and was felt to be of little clinical significance. There was no difference in the global scores between the entacapone and placebo groups.

The home diary variables deteriorated significantly within two weeks of entacapone withdrawal, but no deterioration occurred after withdrawal of placebo. Absolute ON time decreased by 2.1 hours, from 10.9 to 8.8 hours ( $p<0.001 v$ placebo), while OFF time increased by 2.1 hours from 5.5 to 7.6 hours $(\mathrm{p}<0.001 v$ placebo $)$. In addition, the daily levodopa dose requirement was increased by $26 \mathrm{mg}$ after entacapone withdrawal, although this change was not significant.

A trend towards deterioration of UPDRS scores was also seen after withdrawal of entacapone, but this was not statistically significant. The ADL score increased from 11.5 at the month 6 visit to 13.4 at the post-study visit in the entacapone group, while there was no difference in the placebo group. Correspondingly, the motor score increased from 19.0 to 23.4 in the entacapone group, while no change occurred in the placebo group.

\section{Non-fluctuating patients}

The ADL score improved from 10.6 to 10.0 in the entacapone group compared with a reduction of 0.1 in the placebo group $(\mathrm{p}<0.01$; table 4, fig 4). There were no significant differences in the other UPDRS scores or global scores between the entacapone and placebo groups.

The scheduled levodopa dose remained practically unchanged (increased by $7 \mathrm{mg}$ ) in the entacapone group, while it was increased by $47 \mathrm{mg}$ in the placebo group; this difference of $40 \mathrm{mg}$ between the groups was statistically significant $(\mathrm{p}<0.01$; table 4 , fig 3$)$.

The ADL score increased (that is, worsened) from a month 6 visit value of 9.9 to a post-study value of 10.6 after withdrawal of entacapone in the non-fluctuating patient group (NS). There were no significant changes in the scheduled daily levodopa doses in the washout period.

\section{Safety}

Overall, $19 \%$ of the patients in the entacapone group $(\mathrm{n}=38)$ and $14 \%(n=14)$ in the placebo group dropped out of the study because of adverse events. Other reasons for discontinuation were reported in $5 \%$ of patients on entacapone and $2 \%$ of patients on placebo (table 2, fig 1). Diarrhoea was the most

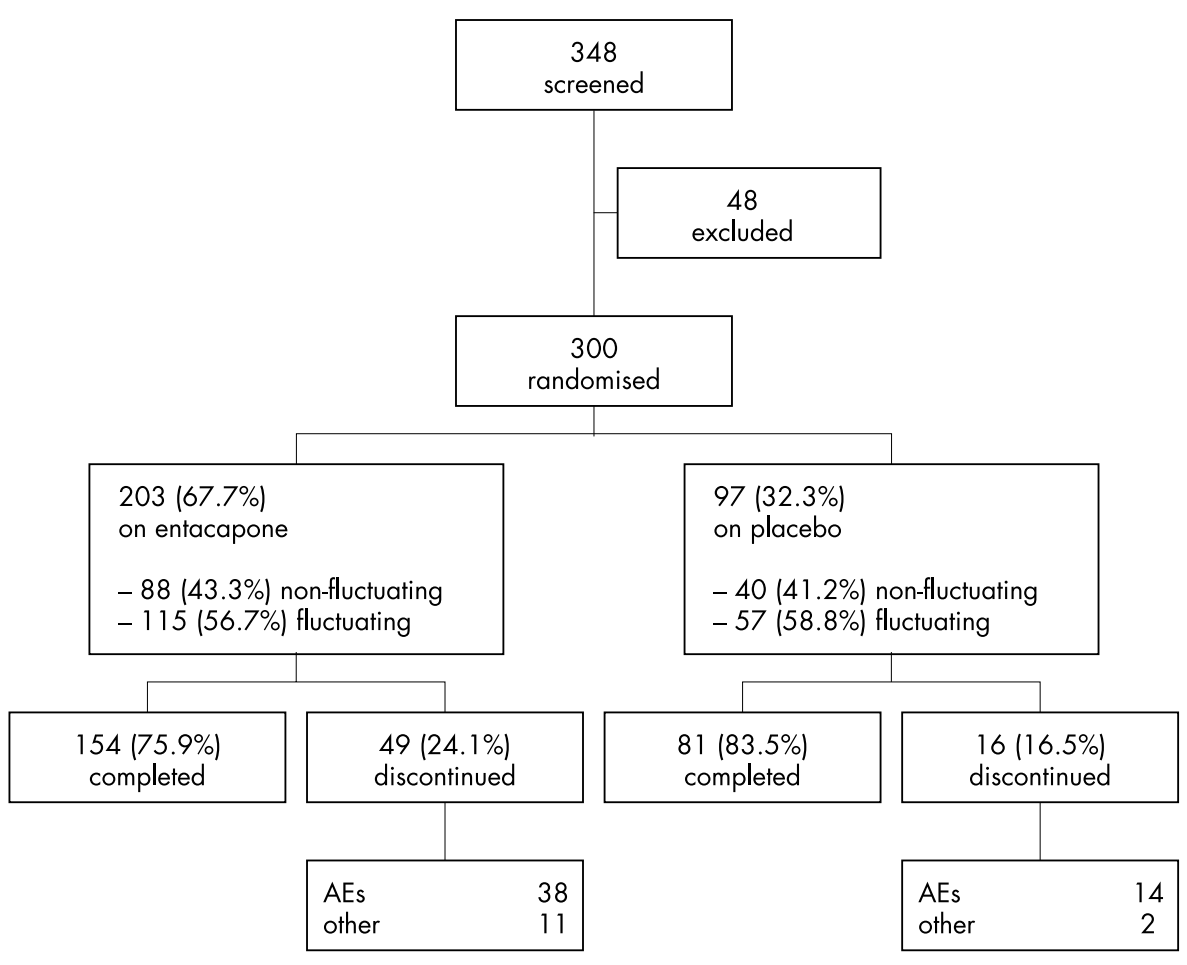

Figure 1 Disposition of all screened patients. AE, adverse event. 
Table 3 Efficacy results for fluctuating patients

\begin{tabular}{|c|c|c|c|c|c|}
\hline \multirow[b]{2}{*}{ Variables } & \multicolumn{2}{|c|}{ Entacapone $(n=115)$} & \multicolumn{2}{|c|}{ Placebo $(n=57)$} & \multirow[b]{2}{*}{$\begin{array}{l}\text { Entacapone } v \\
\text { placebo* }\end{array}$} \\
\hline & $\begin{array}{l}\text { Baseline } \\
(n=115)\end{array}$ & $\begin{array}{l}\text { Mean, months } 4 \\
\text { and } 6(n=80)\end{array}$ & $\begin{array}{l}\text { Baseline } \\
(n=57)\end{array}$ & $\begin{array}{l}\text { Mean, months } 4 \\
\text { and } 6(n=44)\end{array}$ & \\
\hline \multicolumn{6}{|l|}{$\begin{array}{l}\text { Primary efficacy variable } \\
\text { Home diary data }\end{array}$} \\
\hline Proportion ON time (\%) & $57.6(14.5)$ & $64.8(14.0)$ & $59.3(15.8)$ & $60.6(16.7)$ & $p<0.05$ \\
\hline \multicolumn{6}{|l|}{$\begin{array}{l}\text { Secondary efficacy variables } \\
\text { Home diary data }\end{array}$} \\
\hline ON time $(h)$ & $9.5(2.5)$ & $10.8(2.4)$ & $10.1(2.8)$ & $10.2(2.9)$ & $p<0.01$ \\
\hline OFF time (h) & $7.0(2.6)$ & $5.9(2.5)$ & $6.9(2.9)$ & $6.6(2.8)$ & $p<0.05$ \\
\hline Levodopa dose (mg/d) & $700(429)$ & $667(322)$ & $705(368)$ & $731(377)$ & $p<0.001$ \\
\hline \multicolumn{6}{|l|}{ UPDRS } \\
\hline Mentation, behaviour, mood (part I) & $1.7(1.9)$ & $2.0(2.2)$ & $1.4(1.6)$ & $1.5(1.7)$ & $p<0.01$ \\
\hline ADL (part II) & $12.5(5.7)$ & $12.0(5.6)$ & $13.7(6.9)$ & $12.6(7.4)$ & NS \\
\hline Motor score (part III) & $24.3(12.2)$ & $19.8(11.6)$ & $23.6(12.6)$ & $19.3(12.6)$ & NS \\
\hline Total score (I, II, and III) & $38.4(17.3)$ & $33.7(17.0)$ & 38.7 (17.9) & $33.2(20.0)$ & NS \\
\hline Scheduled levodopa dose $(\mathrm{mg} / \mathrm{d})$ & 684 (393) & $667(334)$ & $683(356)$ & 705 (369) & $p<0.001$ \\
\hline $\begin{array}{l}\text { Values are mean (SD). } \\
\text { *Intention to treat-observed cases anal } \\
\text { ADI }\end{array}$ & Date & rating scalo & & & \\
\hline
\end{tabular}

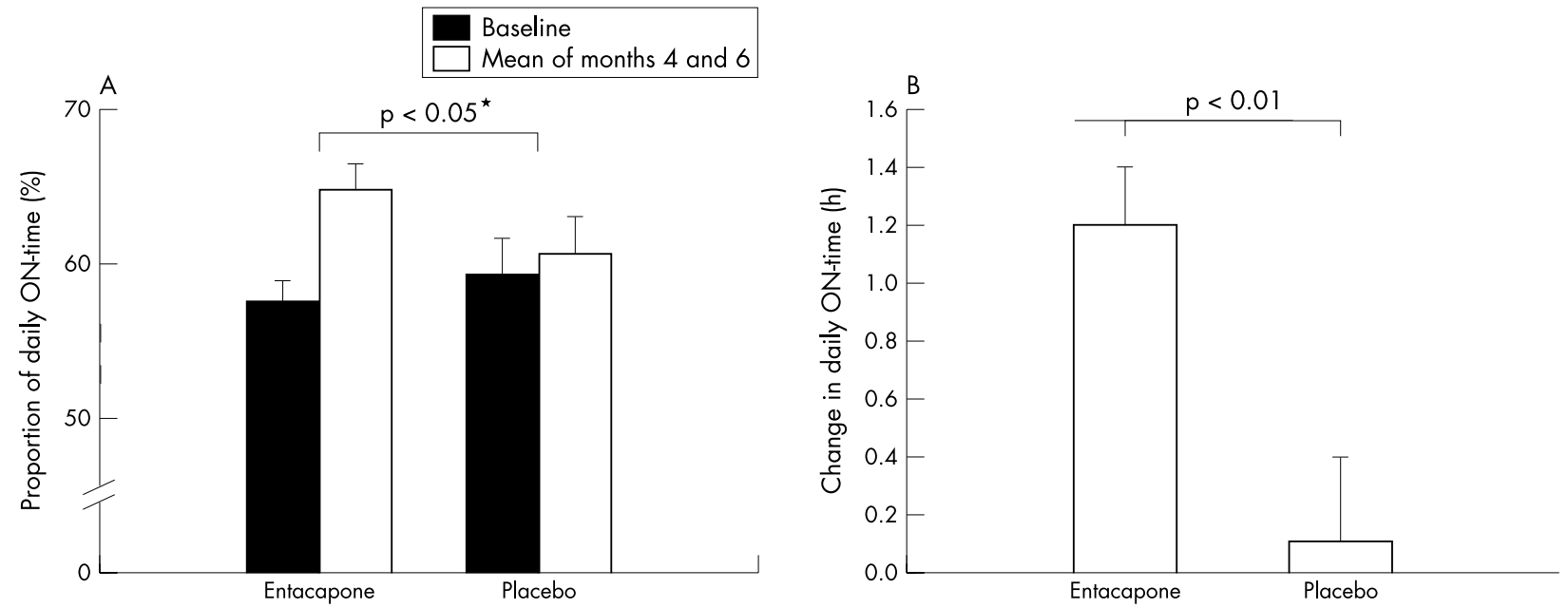

Figure 2 Proportion of daily ON time (\%) (left panel), and change in mean daily ON time (hours) (right panel) from baseline to months 4 and 6 in Parkinson's disease patients with fluctuations. Error bars are SEM. *Comparison between treatment groups, mean of months 4 and 6.
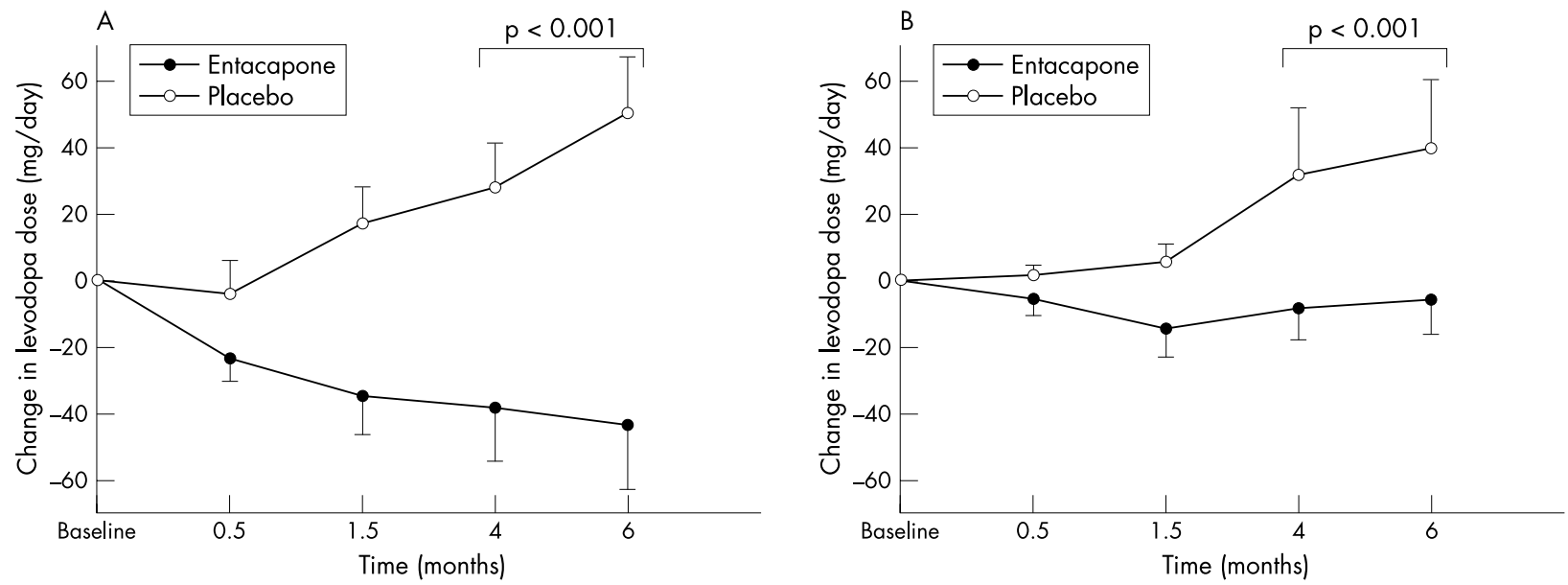

Figure 3 Change in scheduled levodopa dose (mg/day) in Parkinson's disease patients with fluctuations (left panel) and without fluctuations (right panel) during the study. Error bars are SEM. Comparison between treatment groups, mean of months 4 and 6. 

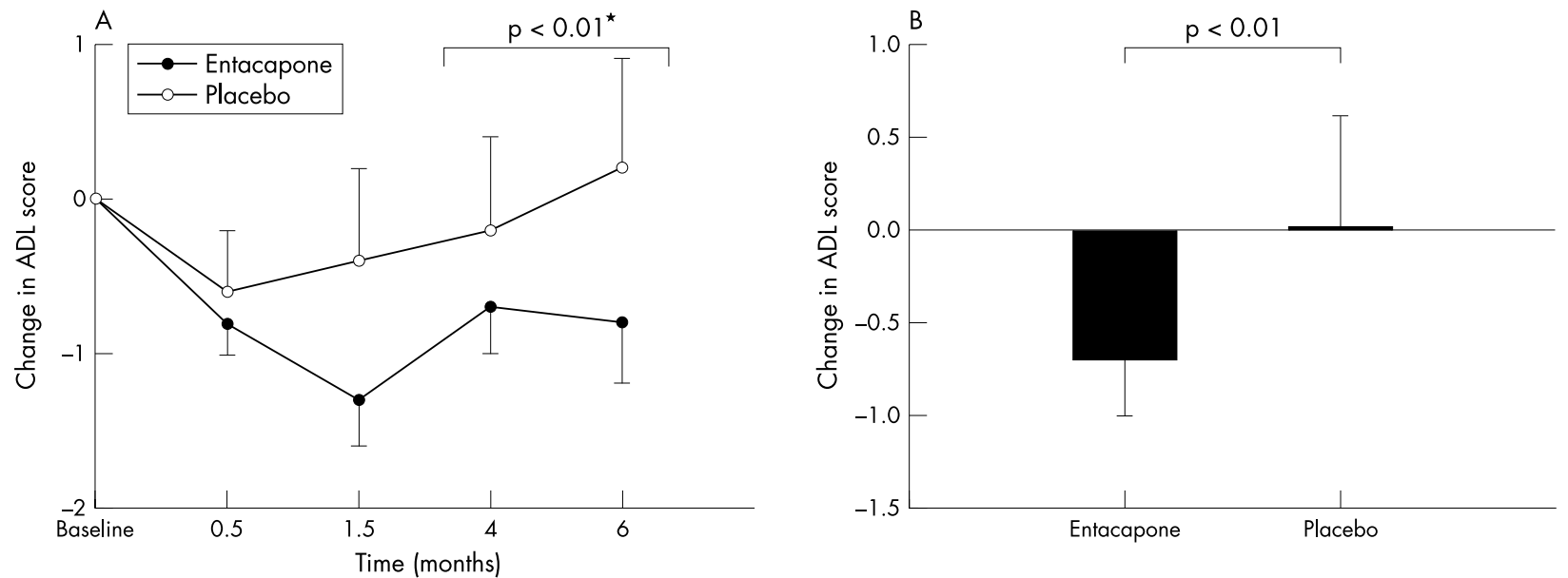

Figure 4 Change in activities of daily living (ADL) score (UPDRS part II) (left panel) during the study, and change from baseline to months 4 and 6 (right panel) in Parkinson's disease patients without fluctuations. Error bars are SEM. *Comparison between treatment groups, mean of months 4 and 6 .

frequent adverse event leading to discontinuation in the entacapone group (4\%), followed by various dopaminergic effects. Aggravation of parkinsonism (worsening of parkinsonian symptoms) led to discontinuation in $3 \%$ of the placebo group and in $1 \%$ of the entacapone group. In the entacapone group, comparable numbers of fluctuating and non-fluctuating patients reported adverse events (91\% v 90\%). In the placebo group adverse events were reported more often by fluctuating than by non-fluctuating patients ( $84 \% v 70 \%)$ (table 5 ).

According to UPDRS question 32 (complications of treatment; occurrence of dyskinesias), $54 \%$ of the patients with fluctuations in the entacapone group and $72 \%$ in the placebo group had dyskinesias at baseline, whereas in patients without fluctuations the corresponding figures were 13\% and $21 \%$ (table 1). Increased dyskinesia was the most common adverse event for fluctuating patients, reported by $30 \%$ in the entacapone group and by $12 \%$ in the placebo group. Dyskinesias were reported as a new adverse event in the nine patients in the entacapone group $(10 \%)$ and in three patients in the placebo group $(8 \%)$. In patients on entacapone with fluctuations, the levodopa dose was reduced in about half the cases; dyskinesias resolved or improved in most of these. In the other half, the levodopa dose was kept practically unchanged. The reduction in daily levodopa dose was in the range of $10-20 \%$. Pergolide was stopped in one patient and dyskinesias resolved. In fluctuating patients on placebo, the levodopa dose was reduced in three subjects and kept unchanged in six. In nonfluctuating patients, increased dyskinesias were reported in
$10 \%$ of the patients in the entacapone group and in $8 \%$ in the placebo group. In the patients on entacapone, the levodopa dose was reduced in three subjects and kept unchanged in nine. Only three subjects had dyskinesia in the corresponding patient group on placebo; no changes were made to their levodopa dose.

In patients with fluctuations, one each in the entacapone and placebo groups reported hallucinations as an adverse event at baseline. Neither of these had worsening of the symptoms during the study period. Six patients $(5 \%)$ in the entacapone group and three $(5 \%)$ in the placebo group reported getting hallucinations during the study. One patient with fluctuations in the entacapone group and two with fluctuations in the placebo group dropped out of the study because of hallucinations. In three patients on entacapone, the levodopa dose was reduced, and in one, pergolide was discontinued. The problems resolved in all these patients. One patient in the placebo group had mild hallucinations; no action was taken and the hallucinations remained unchanged. In patients without fluctuations, one in the entacapone but none in the placebo group reported hallucinations at baseline. Six patients (7\%) in the entacapone group and one $(3 \%)$ in the placebo group reported getting hallucinations during the study. Two patients on entacapone and one on placebo dropped out of the study. The levodopa dose was reduced in one patient on entacapone and the hallucinations disappeared. In the patient in the placebo group, the mild hallucinations resolved spontaneously.

Table 4 Efficacy results for non-fluctuating patients

\begin{tabular}{|c|c|c|c|c|c|}
\hline \multirow[b]{2}{*}{ Variables } & \multicolumn{2}{|c|}{ Entacapone $(n=87)$} & \multicolumn{2}{|c|}{ Placebo $(n=38)$} & \multirow[b]{2}{*}{$\begin{array}{l}\text { Entacapone v } \\
\text { placebo* }\end{array}$} \\
\hline & $\begin{array}{l}\text { Baseline } \\
(\mathrm{n}=87)\end{array}$ & $\begin{array}{l}\text { Mean, months } 4 \\
\text { and } 6 \text { ( } n=78)\end{array}$ & $\begin{array}{l}\text { Baseline } \\
(\mathrm{n}=38)\end{array}$ & $\begin{array}{l}\text { Mean, months } 4 \\
\text { and } 6 \text { ( }(n=37)\end{array}$ & \\
\hline \multicolumn{6}{|l|}{ Primary efficacy variable } \\
\hline \multicolumn{6}{|l|}{ UPDRS } \\
\hline ADL† (part II) & $10.6(5.7)$ & $10.0(5.7)$ & $9.5(4.2)$ & $9.4(5.7)$ & $p<0.01$ \\
\hline \multicolumn{6}{|l|}{$\begin{array}{l}\text { Secondary efficacy variables } \\
\text { UPDRS }\end{array}$} \\
\hline Mentation, behaviour, mood (part I) & $1.5(1.5)$ & $1.8(1.5)$ & $1.2(1.3)$ & $1.1(1.1)$ & NS \\
\hline Motor score (part III) & $23.4(11.7)$ & $20.9(12.4)$ & $22.4(9.8)$ & $17.4(10.2)$ & NS \\
\hline Total score (II, II, and III) & $35.2(16.6)$ & 32.7 (17.5) & $33.0(12.5)$ & $27.8(14.5)$ & NS \\
\hline Scheduled levodopa dose $(\mathrm{mg} / \mathrm{d})$ & $503(259)$ & $510(253)$ & $522(343)$ & $569(365)$ & $p<0.01$ \\
\hline
\end{tabular}

Values are mean (SD)

*Intention to treat-observed cases analysis.

ADL, activities of daily living; UPDRS, unified Parkinson's disease rating scale. 
Table 5 Adverse events (> 5\% incidence in either the entacapone or placebo group) in fluctuating and non-fluctuating patients

\begin{tabular}{|c|c|c|c|c|c|c|c|c|}
\hline \multirow[b]{3}{*}{ Adverse event } & \multicolumn{4}{|c|}{ Fluctuating patients $(n=172)$} & \multicolumn{4}{|c|}{ Non-fluctuating patients $(n=128)$} \\
\hline & \multicolumn{2}{|c|}{$\begin{array}{l}\text { Entacapone } \\
(n=115)\end{array}$} & \multicolumn{2}{|c|}{$\begin{array}{l}\text { Placebo } \\
(n=57)\end{array}$} & \multicolumn{2}{|c|}{$\begin{array}{l}\text { Entacapone } \\
(n=88)\end{array}$} & \multicolumn{2}{|c|}{$\begin{array}{l}\text { Placebo } \\
(n=40)\end{array}$} \\
\hline & $\mathrm{n}$ & $\%$ & $\mathrm{n}$ & $\%$ & $\mathrm{n}$ & $\%$ & $\mathrm{n}$ & $\%$ \\
\hline Dyskinesia & 35 & 30.4 & 7 & 12.3 & 9 & 10.2 & 3 & 7.5 \\
\hline Parkinsonism aggravated* & 21 & 18.3 & 15 & 26.3 & 8 & 9.1 & 2 & 5.0 \\
\hline Urine abnormal & 20 & 17.4 & 0 & 0 & 10 & 11.4 & 0 & 0 \\
\hline Nausea & 17 & 14.8 & 5 & 8.8 & 15 & 17.0 & 2 & 5.0 \\
\hline Constipation & 14 & 12.2 & 1 & 1.8 & 7 & 8.0 & 3 & 7.5 \\
\hline Dizziness & 13 & 11.3 & 3 & 5.3 & 7 & 8.0 & 1 & 2.5 \\
\hline Diarrhoea & 13 & 11.3 & 2 & 3.5 & 12 & 13.6 & 1 & 2.5 \\
\hline Depression & 8 & 7.0 & 4 & 7.0 & 3 & 3.4 & 2 & 5.0 \\
\hline Pain & 8 & 7.0 & 2 & 3.5 & 3 & 3.4 & 3 & 7.5 \\
\hline Fall & 8 & 7.0 & 7 & 12.3 & 2 & 2.3 & 0 & 0 \\
\hline Hallucination & 6 & 5.2 & 3 & 5.3 & 6 & 6.8 & 1 & 2.5 \\
\hline Abdominal pain & 6 & 5.2 & 3 & 5.3 & 4 & 4.5 & 0 & 0 \\
\hline Fatigue & 5 & 4.3 & 4 & 7.0 & 8 & 9.1 & 1 & 2.5 \\
\hline Patients with any $A E$ & 105 & 91.3 & 48 & 84.2 & 79 & 89.9 & 28 & 70.0 \\
\hline
\end{tabular}

Diarrhoea occurred in $12 \%$ of patients receiving entacapone (fluctuators and non-fluctuators) and in 3\% of patients on placebo. Diarrhoea was reported several weeks after the introduction of entacapone, in contrast to dopaminergic adverse events, in which the onset is more rapid. Diarrhoea was the cause of discontinuation in five patients with fluctuations in the entacapone group (4\%), and in one $(2 \%)$ in the placebo group. Of the non-fluctuating patients, four (5\%) on entacapone and none on placebo dropped out of the study because of diarrhoea.

There were only occasional minor abnormalities in the individual haematological, clinical chemistry, or urine values in the entacapone group compared with baseline; the few of these considered to be of clinical significance are not reported as being connected with entacapone treatment. Neither vital signs nor ECG tracings raised safety concerns. No drug-drug interactions were reported.

\section{DISCUSSION}

The results of this double blind, placebo controlled, six month study confirm that treatment with entacapone improves the efficacy of levodopa treatment in patients with Parkinson's disease who are experiencing motor fluctuations. The study also suggests that the benefits afforded by combining levodopa with entacapone may be extended to patients who are not experiencing motor fluctuations.

The beneficial effects of combining entacapone with levodopa on the management of fluctuating Parkinson's disease seen in our study are in accordance with reported results from four other phase III, randomised, double blind, placebo controlled studies in patients on entacapone. ${ }^{28-31}$ The results are also in accordance with phase III tolcapone studies in fluctuating patients. ${ }^{31-37}$ In the present study, the daily ON time was significantly improved by 1.2 hours, and the OFF time correspondingly reduced, with entacapone compared with placebo. This was despite apparent individual optimisation of the levodopa and other antiparkinsonian drug treatment before entry to the trial. Previous phase III trials have found that the use of entacapone increases ON time with levodopa by 1.0 to 1.7 hours. In the present trial, these benefits were achieved despite a significant reduction in the daily levodopa dose, as seen in other phase III controlled entacapone studies as well.$^{28} 2931$
Both standard and CR levodopa preparations were used in the present study. Previous trials have shown that entacapone prolongs the clinical response to standard and CR levodopa preparations to a similar degree, as evaluated by levodopa challenge ${ }^{38}{ }^{39}$ and home diaries. ${ }^{31}$ Thus the use of these different levodopa preparations in this trial should not have been a confounding factor.

A methodological challenge in choosing the primary end point for the non-fluctuator patient population was the selection of the most appropriate efficacy index, given that no applicable home diary data were available. In the absence of a validated Parkinson's disease specific quality of life scale when the trial was designed, the ADL score was regarded as a relevant primary efficacy index..$^{40}$ In a tolcapone study in Parkinson's disease patients without fluctuations, Waters et al also used the ADL score as the primary end point. ${ }^{26}$ In the present study, the a priori selected ADL score improved in patients with non-fluctuating disease given entacapone compared with placebo. This is in agreement with results with tolcapone in the placebo controlled trial reported by Waters et al, ${ }^{26}$ which had a similar patient population and a similar study design. In that study, the daily levodopa dose was also significantly reduced.

Recent evaluations have shown a strong association between measures of ADL and health related quality of life, ${ }^{41}$ indicating that it may be possible to improve these patients' quality of life further by adding a COMT inhibitor. This will need to be confirmed with additional trials in non-fluctuating patients using disease specific quality of life scales-for example, the Parkinson's disease questionnaire 39 (PDQ-39) scale $^{42}$-which have shown in previous studies that the benefits of entacapone treatment translate into improvements in quality of life in patients experiencing motor fluctuations. ${ }^{43}$

There was no difference in the motor score of the UPDRS between the entacapone and placebo groups in the present study. This was not unexpected, as entacapone increases the bioavailability of levodopa by prolonging its elimination but not by affecting its peak concentrations; this leads to a longer duration of effect of levodopa. ${ }^{21-23}$ The motor score indicates function scored at a particular time point, while the ADL depicts the state of the patient over a longer period.

Common treatment practice is to wait until the patient begins to experience motor fluctuations before initiating treatment with a COMT inhibitor. ${ }^{8}$ However, the improvement 
in ADL score achieved with entacapone in non-fluctuating disease suggests that the general condition of these less severely affected patients is not optimal despite their apparent response to levodopa. Interestingly, an increase in daily levodopa dose by $40 \mathrm{mg}$ in the placebo treated compared with entacapone treated non-fluctuating patients did not result in a similar improvement in ADL scores. Thus starting entacapone may prove beneficial at this stage of the disease, if future studies confirm the present findings.

Entacapone was well tolerated in our present study in both fluctuating and non-fluctuating patients. COMT inhibition is thus an alternative for increasing the dosing frequency of levodopa in this particular patient group.

Dyskinesias usually emerge some years after the emergence of motor fluctuations. However, in some patients the order may be reversed. ${ }^{7}$ In the present study some $10-20 \%$ of the non-fluctuating patients were already reporting mild peak dose dyskinesias at baseline. Again, even in this respect the patient population in our study resembles that described by Waters et al. ${ }^{26}$ The safety profile was similar to that previously reported in other controlled, double blind, phase III studies ${ }^{28-31}$ As expected, dopaminergic adverse events were the most common. Thus the prevalence of dyskinesias increased during the first days after initiating entacapone, but reverted to baseline with a reduction in the levodopa dose. As in previous studies, diarrhoea was the most common nondopaminergic adverse event. About $4 \%$ of the patients with diarrhoea dropped out of the study-comparable to the $2-3 \%$ in previous long term studies. Diarrhoea did not usually occur immediately after starting entacapone but rather after some weeks, in contrast to the appearance of dopaminergic adverse events. There were no clinically relevant safety problems in the haematological or biochemical laboratory tests, vital signs, or ECG changes. As in previous studies, no indication of liver toxicity was found. Entacapone was initially licensed about four years ago in many countries, and over 100000 patients have been safely treated with this agent to date.

\section{Conclusions}

The results of this UK-Irish trial confirm that peripheral COMT inhibition with entacapone improves the management of levodopa treated patients with Parkinson's disease and motor fluctuations. As entacapone is easy to take, well tolerated, and potentially reduces the development of motor complications, ${ }^{44}$ it appears logical to employ levodopa combined with entacapone routinely for the effective management of this group of patients. Moreover, as evidenced by an improvement in their ADL scores, levodopa treated patients who are not yet suffering from clear motor fluctuations may also benefit from entacapone.

\section{APPENDIX}

\section{LIST OF INVESTIGATORS}

\section{The UK-Irish Study Group}

H J Sagar (Principal Investigator), R Grunevald, J Sussman: The University of Sheffield, Sheffield; D J Brooks (co-principal Investigator), P Piccini: Hammersmith Hospital, London; R Chaudhuri, H Wilson, A Winkler, M Hu: King's College Hospital, London; C E Clarke: Hull Royal Infirmary, Hull; G V Sawle: Queen's Medical Centre, Nottingham; N P Quinn, H Nees, S Costa: The National Hospital for Neurology and Neurosurgery, London; A Williams, D Nicholl: Queen Elizabeth Hospital, Birmingham; D Burn: Royal Victoria Infirmary, Newcastle-uponTyne; D G MacMahon, J Lack, R Bland: Camborne and Redruth Community Hospital, Cornwall; P Fletcher, A Thu: Delancey Hospital, Gloucestershire; D R Forsyth: Addenbrooke's Hospital, Cambridge; D Robertson, R Jones, G Mann: St Martin's Hospital, Bath; B Gastleton: St Peter's Hospital NHS Trust, Surrey; E Spokes: Leeds General Infirmary, Leeds;
B Boothman: Blackpool Victoria Hospital, Blackpool; M Murphy, D O'Connell, P Fitzgerald: The Mercy Hospital, Cork; D Grosset: Southern Central Hospital, Glasgow; A C Young: Hope Hospital, Salford; J V Hindle: Llandudo General Hospital, Cwynedd.

\section{Safety Monitoring Committee}

J MacDermot (Chairman): Hammersmith Hospital, London; D Parkes (Clinical neurologist): Institute of Psychiatry, London; S Thomson (statistical advisor): Hammersmith Hospital, London.

\section{Orion Pharma personnel}

K Reinikainen, A Gordin, E-R Kultalahti, P Wall, M Häyhä, H Haapaniemi, M Leinonen, H Ahtinen.

\section{Authors' affiliations}

D J Brooks, Division of Neuroscience, Faculty of Medicine, Imperial College, Hammersmith Hospital, London, UK

H Sagar, Department of Clinical Neurology, Royal Hallamshire Hospital, University of Sheffield, Sheffield, UK

Competing interests: DB has been reimbursed by Orion Pharma, the manufacturers of entacapone, for attending several conferences and has received honoraria. He has also served on national and international advisory boards for Orion Pharma.

\section{REFERENCES}

1 Nutt JG. Catechol-O-methyltransferase inhibitors for treatment of Parkinson's disease. Lancet 1998;351:1221-2.

2 Agid Y, Ahlskog E, Albanese A, Members of the Consensus Meeting Levodopa in the treatment of Parkinson's disease: a consensus meeting. Mov Disord 1999;14:911-13.

3 Nutt JG, Holford NHG. The response to levodopa in Parkinson's disease: imposing pharmacological law and order. Ann Neurol 1996;39:561-73

4 Marsden CD, Parkes JD. "ON-OFF" effects in patients with Parkinson's disease on chronic levodopa therapy. Lancet 1976;i:292-6.

5 The Parkinson Study Group. Effects of tocopherol and deprenyl on the progression of disability in early Parkinson's disease. N Engl J Med 1993;328:176-83

6 Block G, Liss C, Reines S, and the CR First Study Group. Comparison of immediate-release and controlled release carbidopa/levodopa in Parkinson's disease: a multicenter 5-year study. Eur Neurol 1997;37:23-7.

7 Larsen JP, Karlsen K, Tandberg E. Clinical problems in non-fluctuating patients with Parkinson's disease: a community-based study. Mov Disord 2000;5:826-9.

8 Schapira AHV, Obeso JA, Olanow CW. The place of COMT inhibitors in the armamentarium of drugs for the treatment of Parkinson's disease. Neurology 2000;55(suppl 4):65-8.

9 Waters C. Catechol-O-methytransferase (COMT) inhibitors in Parkinson's disease. J Am Geriatric Soc 2000;48:692-8.

10 Koller WC, Hutton JT, Tolosa E, and the Carbidopa/Levodopa Study Group. Immediate-release and controlled-release carbidopa/levodopa in PD: a 5-year randomized multicenter study. Neurology 1999:53:1012-19.

11 Yeh KC, August TF, Bush DF, et al. Pharmacokinetics and bioavailability of Sinemet CR: a summary of human studies. Neurology 1989;39/suppl 2):25-38.

12 Hutton J, Morris J. Therapeutic advances of sustained release levodopa formulation. CNS Drugs 1994;2:110-19.

13 Pahwa R, Lyons K, McGuire D, et al. Comparison of standard carbidopa-levodopa and sustained-release carbidopa-levodopa in Parkinson's disease: pharmacokinetic and quality-of-life measures. Mov Disord 1997; 12:677-81.

14 Kaakkola S, Gordin A, Männistö P. General properties and clinical possibilities of new selective inhibitors of catechol-O-methyltransferase. Gen Pharmacol 1994;25:813-24.

15 Kaakkola S. Clinical pharmacology, therapeutic use and potential of COMT inhibitors in Parkinson's disease. Drugs 2000;59:1233-50.

16 Nissinen E, Linden IB, Schultz E, et al. Biochemical and pharmacological properties of a peripherally acting catechol-O-methyltransferase inhibitor entacapone. Naunyn Schmiedebergs Arch Pharmacol 1992;346:262-6

17 Bonifati V, Meco G. New, selective catechol-O-methyltransferase inhibitors as therapeutic agents in Parkinson's disease. Pharmacol Ther 1999;81:1-36.

18 Keränen T, Gordin A, Harjola VP, et al. The effect of catechol-O-methyltransferase inhibition by entacapone on the pharmacokinetics and metabolism of levodopa in healthy volunteers. Clin Neuropharmacol 1993;16:145-56.

19 Merello M, Lees AV, Webster R, et al. Effect of entacapone, a peripherally acting catechol-O-methyltransferase inhibitor, on the motor 
response to acute treatment with levodopa in patients with Parkinson's disease. J Neurol Neurosurg Psychiatry 1994;57:186-9.

20 Nutt JG, Woodward WR, Beckner RM, et al. Effect of peripheral catechol-O-methyltransferase inhibition on the pharmacokinetics and pharmacodynamics of levodopa in parkinsonian patients. Neurology 1994:44:913-19.

21 Ruottinen HM, Rinne UK. A double-blind pharmacokinetic and clinical dose-response study of entacapone as an adjuvant to levodopa therapy in advanced Parkinson's disease. Clin Neuropharmacol

1996;19:283-96.

22 Ruottinen HM, Rinne UK. Effect of one month's treatment with peripherally acting catechol-O-methyltransferase inhibitor, entacapone, on pharmacokinetics and motor response to levodopa in advanced parkinsonian patients. Clin Neuropharmacol 1996;19:222-33.

23 Ruottinen HM, Rinne UK. Entacapone prolongs levodopa response in a one month double blind study in parkinsonian patients with levodopa related fluctuations. J Neurol Neurosurg Psychiatry 1996;60:36-40.

24 Baas H, Zehrden F, Selzer R, et al. Pharmacokinetic-pharmacodynamic relationship of levodopa with and without tolcapone in patients with Parkinson's disease. Clin Pharmacokin 2001;40:383-93.

25 Karlsen KH, Tandberg E, Årsland D, et al. Health related quality of life in Parkinson's disease: a prospective longitudinal study. J Neurol Neurosurg Psychiatry 2000;69:584-9.

26 Waters $\mathbf{C H}$, Kurth M, Bailey P, et al. Tolcapone in stable Parkinson's disease. Neurology 1997:49:665-71.

27 Suchowersky O, Bailey P, Pourcher E, et al. Comparison of two dosages of tolcapone added to levodopa in nonfluctuating patients with PD. Clin Neuropharmacol 2001;24:214-20.

28 Parkinson Study Group. Entacapone improves motor fluctuations in levodopa-treated Parkinson's disease patients. Ann Neurol 1997; 42:747-55

29 Rinne UK, Larsen JP, Siden $\AA$, and the Nomecomt Study Group. Entacapone enhances the response to levodopa in parkinsonian patients with motor fluctuations. Neurology 1998;51:1309-14.

30 Myllylä VV, Kultalahti E-R, Haapaniemi H, and the Filomen Study Group. Twelve-months safety of entacapone in patients with Parkinson's disease. Eur J Neurol 2001;8:53-60

31 Poewe W, Deuschl G, Gordin A, and the Celomen Study Group. Efficacy and safety of entacapone in Parkinson's disease patients with suboptimal levodopa response: a six-months randomized placebo-controlled double-blind study in Germany and Austria (Celomen study). Acta Neurol Scand 2002;105:1-11

32 Fahn S, Elton R, and Members of the UPDRS Development Committee. Unified Parkinson's disease rating scale. In: Fahn S, Marsden CD, Calne $D$, et al, eds. Recent developments in Parkinson's disease. Florom Park: Macmillan, 1987:153-63.
33 Baas H, Beiske AG, Ghika J, et al Catechol-O-methyl-transferase inhibition with tolcapone reduces the "wearing off" phenomenon and levodopa requirements in fluctuating parkinsonian patients. J Neurol Neurosurg Psychiatry 1997;63:421-8.

34 Kurth MC, Adler CH, Hilaire MS, et al. Tolcapone improves motor function and reduces levodopa requirement in patients with Parkinson's disease experiencing motor fluctuations: a multicenter, double-blind, randomized, placebo-controlled trial. Tolcapone Fluctuator Study Group I. Neurology 1997;48:81-7.

35 Myllylä VV, Jackson M, Larsen JP, et al. Efficacy and safety of tolcapone in levodopa-treated Parkinson's disease patients with "wearing-off" phenomenon: a multicentre, double-blind, randomized placebo-controlled study. Eur J Neurol 1997;4:333-41.

36 Rajput AH, Martin W, Sainthilaire MH, et al. Tolcapone improves motor function in parkinsonian patients with the "wearing-off" phenomenon: a double-blind, placebo-controlled, multicenter trial. Neurology 1997;49:1066-71.

37 Adler $\mathbf{C H}$, Singer $\mathrm{C}, \mathrm{O}^{\prime}$ Brien $\mathrm{C}$, et al. Randomized, placebo-controlled study of tolcapone in patients with fluctuating Parkinson disease treated with levodopa-carbidopa. Arch Neurol 1998;55:1089-95.

38 Kaakkola S, Teräväinen $\mathrm{H}$, Ahtila S, et al. Entacapone in combination with standard or controlled-release levodopa/carbidopa: a clinical and pharmacokinetic study in patients with Parkinson's disease. Eur J Neurol 1995;2:341-7.

39 Piccini P, Brooks DJ, Korpela K, et al. The catechol-O-methyltransferase (COMT) inhibitor entacapone enhances the pharmacokinetic and clinical response to Sinemet CR in Parkinson's disease. J Neurol Neurosurg Psychiatry 2000;68:589-94

40 Committee for Proprietary Medicinal Products (CPMP). European Economic Community. Note for guidance: clinical investigation of medicinal products in the treatment of Parkinson's disease. Eur Neuropsychopharmacol 1999;9:443-9

41 Hobson JP, Edwards NI, Meara RJ. The Parkinson's disease Activities of Daily Living scale: a new simple and brief subjective measure of disability in Parkinson's disease. Clin Rehabil 2001;15:241-6.

42 Jenkinson C, Fitzpatrick R, Peto V. Health related quality-of-life measurement in patients with Parkinson's disease. Pharmacoeconomics 1999; 15:157-65

43 Durif F, Devaux J-J, Pere J-J et al. Efficacy and tolerability of entacapone as an adjunctive therapy to levodopa in patients with Parkinson's disease and end-of-dose deterioration in daily medical practice: an open, multicenter study. Eur Neurol 2001;45:111-18

44 Olanow CW, Obeso JA. Pulsatile stimulation of dopamine receptors and levodopa-induced motor complications in Parkinson's disease. Implications for the early use of COMT inhibitors. Neurology 2000;55(suppl 4):72-7. 